\title{
Revealing key parameters to minimize the diameter of polypropylene fibers produced in the melt electrospinning process
}

https://doi.org/10.1515/epoly-2019-0034

Received October 31, 2018; accepted January 30, 2019.

\begin{abstract}
This study deals with the subject of optimizing the melt electrospinning process of polypropylene with the aim of producing nanoscale fibers. A feasibility study with two polypropylene types and different additives to adapt the material composition is performed. The polypropylene types are of different molar masses to adapt the viscosity to the process. The used additives, sodium stearate and Irgastat ${ }^{\circledR}$ P 16 , have a positive effect on the electrical conductivity of the polymer melt. In addition, process parameter optimization is done by varying the climate chamber temperature, using different collector voltages and varying the nozzle-collector distance. A strong influence of the climate chamber temperature has been proven and leads to a desired temperature of $100^{\circ} \mathrm{C}$. The fiber diameter is dependent on process parameters, material melt viscosity and electrical conductivity. With optimized process and material parameters, the fiber diameter could be minimized to a median value of $210 \mathrm{~nm}$.
\end{abstract}

Keywords: melt electrospinning; polypropylene; sodium stearate; nanofibers; process optimizing

\section{Introduction}

There are a variety of methods available for the production of polypropylene fibres, which can be divided into melt

\footnotetext{
* Corresponding author: Dirk W. Schubert, Institute of Polymer Materials, Friedrich-Alexander-University Erlangen-Nürnberg (FAU), Martensstraße 7, 91058 Erlangen, Germany; Bavarian Polymer Institute, Dr.-Mack-Straße 77, 90762 Fürth, Germany, email: dirk.schubert@fau.de.

Jonas Daenicke, Michael Lämmlein and Felix Steinhübl, Institute of Polymer Materials, Friedrich-Alexander-University ErlangenNürnberg (FAU), Martensstraße 7, 91058 Erlangen, Germany.
}

and solution based methods or wet and dry processes. Typically, polypropylene fiber production is melt based and can be classified into methods such as melt blowing, melt spinning with subsequent fiber stretching and melt electrospinning (1-3). In addition to melt blowing, electrospinning is the most common technique for the production of nanoscale fibers, which is unique due to its compact experimental setup and its applicability to a large number of polymers (3-6). The production of polymer fibers using the electrospinning process was first described in detail in a patent by A. Formhals in 1934 (7). However, in contrast to this investigation, the processing was carried out from a polymer solution. Electrospinning from polymer melt was first published in detail by Larrondo et al. in 1981 (8-10), but due to the high viscosity of the melt compared to a polymer solution only polymer fibers with a diameter in the micrometer range could be achieved (11). It was observed that a fiber of molten polymer undergoes a significant reduction of its diameter in the electric field, whereby an increase of the field strength could reinforce this effect (12). Due to the more complex experimental setup and the more demanding process conditions of melt electrospinning, more research has focused on solution electrospinning than on melt electrospinning in recent years $(11,13)$. Polypropylene, which is the focus of this study, can only be solution spun to a limited extent. Due to the high solvent resistance of the polymer, there is only a small selection of solvents that allow further processing, some of them allow dissolution only at elevated temperatures. Nevertheless, there are some studies on processability and fiber analysis of polypropylene fibers spun by solvent electrospinning (14-17). A study by Cho et al. compares the solution and melt electrospinning of polypropylene. With both methods, fibers in the submicron range were spun (14). Another work, carried out by Maeda et al., succeeded in solvent electrospinning at ambient temperature with methylcyclohexane as solvent. Polypropylene fibres with an average diameter of $230 \mathrm{~nm}$ were achieved (15). 
For the realization of the melt spinning of polypropylene there are a variety of different approaches, Cao et al. analyzed the process with a copolymer blend of a styrene-acrylonitrile and a polypropylene. The styreneacrylonitrile served as a polymeric nucleating agent. Fibers with a diameter of 5-10 $\mu \mathrm{m}$ were achieved, whereby the focus of the work is on the evaluation of the fiber morphology and the crystallization behavior (18). A further studyby Caoetal.showed that the addition of a $\beta$-nucleating agent improves the melt electrospinning process of polypropylene and reduces the fiber diameter below $5 \mu \mathrm{m}$. The effects of the nucleating agent on mechanical, morphological and crystallization properties have been investigated (19). Application-specific multi-wall carbon nanotube/polypropylene fiber webs have been produced as conductive membranes in the melt electrospinning process. The orientation of the carbon nanotubes and the crystallization behavior of the fibers with a diameter of 1-3 $\mu \mathrm{m}$ have been evaluated (20).

The main focus of this study, the minimization of the fiber diameter by optimizing the polymer compound and the process parameters, has already been approached in several studies. In order to reduce the diameter of polypropylene melt electrospinning fiber process parameters such as process temperature, applied collector voltage and nozzle-collector distance were first optimized (21). In a research project by Dalton et al., material parameters such as viscosity have been optimized to reduce the fiber diameter. By adding viscosity reducing additives such as Irgatec $®$ from BASF SE, the reduction of the average fiber diameter from $35.6 \pm 1.7 \mu \mathrm{m}$ to $840 \pm 190 \mathrm{~nm}$ was achieved (22). Another approach by Nayak et al. involves the use of rheology modifiers such as polyethylene glycol and polydimethylsiloxane to reduce viscosity (11). Nevertheless, it has not been possible to produce nanofibers with the addition of these modifiers alone. As a result, Nayak et al. increased the electrical conductivity of the polypropylene melt (Polypropylene with a MFI of $2000 \mathrm{~g} / 10 \mathrm{~min}$ ) by adding additives such as sodium oleate and sodium chloride. Thereby, an average fiber diameter of $310 \mathrm{~nm}$ has been achieved under optimal conditions using sodium chloride (23). With a comparable approach by Chen et al. in 2014, the addition of polar additives such as sodium stearate and stearic acid resulted in an average fiber diameter of only $1.8 \mu \mathrm{m}$ (24). In this study, the fiber diameter is to be minimized to the nanometer range by optimizing the polypropylene compound with the addition of a low molar mass polyolefin, sodium stearate and an antistatic agent at certain concentrations. Furthermore, the experimental setup is optimized and extended in a targeted manner in order to achieve the goal of this work: a homogeneous fiber diameter in the nanometer range.

\section{Experimental}

\subsection{Materials}

The present study uses the polypropylene homopolymer HL712FB from Borealis AG. This material is a stable thermoplastic and chemically inert polymer. It is specially designed for fiber spinning applications by the meltblown process. The material has the following relevant properties in regard to the melt electrospinning process: a melting point of $158^{\circ} \mathrm{C}$, a narrow molar mass distribution and a melt flow rate of $1200 \mathrm{~g} / 10 \mathrm{~min}$ (25). An additional low molar mass polyolefin, L-Modu ${ }^{\mathrm{TM}} \mathrm{S} 400$ from Idemtisu Kosan Co. Ltd., is added to the compound to further reduce the viscosity in the molten state. L-Modu ${ }^{\mathrm{TM}}$ S400 has a melting point of $80^{\circ} \mathrm{C}$ and a melt flow rate of $2600 \mathrm{~g} / 10 \mathrm{~min}$. The short designation L-Modu is a byword for a low molar mass and low modulus polypropylene (26). The two components are mixed in a relation of nine parts HL712FB and one part L-Modu ${ }^{\mathrm{TM}}$ S400 according to preliminary tests, which have been carried out in a supplementary study.

To achieve the desired material specifications with regard to conductivity and viscosity, sodium stearate and the antistatic agent $\operatorname{Irgastat}{ }^{\circledR}$ P 16 from BASF SE are added in varied amounts. To increase the electrical conductivity of the polymer material sodium stearate from Alfa Aesar is used as additive. The salt ions introduce additional charge carriers into the polymer melt, which, due to the electrostatic repulsion, are intended to promote the stretching of the fibers in the spinning process. The sodium salt is in powder form and has a softening point of $200-240^{\circ} \mathrm{C}$ (27). Furthermore, the polyamide/polyether block copolymer Irgastat ${ }^{\circledR}$ P 16 is added, which causes a permanent antistatic effect. Irgastat ${ }^{\circledR}$ P 16 has a melting point of $158^{\circ} \mathrm{C}$ and is therefore well suited for process applications with polypropylene (28). The use of this antistatic agent is necessary because polypropylene, as an electrical insulator, inherently accumulates electrical charges on the surface. The effect of the so-called internal antistatic agents, which also includes Irgastat ${ }^{\circledR}$ P 16, consists in their migration to the surface and the subsequent formation of a conductive layer on which the charges can be distributed (29). In this way, agglomeration of the electrical loads is prevented and thus a more homogeneous distribution is achieved. 
The polypropylene is compounded with the selected additives, utilizing an extruder from Leistritz $\mathrm{AG}$ (Type: LSM $34 \mathrm{GL}$ ). A melting temperature of $180^{\circ} \mathrm{C}$ and a screw speed of $16.0 \mathrm{rpm}$ is selected. The compounded material is then granulated (Type: C13.20sv, Wanner Technik GmbH).

\subsection{Material characterization}

The different polypropylene compounds are then analysed with regard to their thermal properties. Differential scanning calorimetry (DSC) is used to determine the effect of additives on the melting temperature. A DSC of the type Q2000 from TA Instruments has been used for the measurements. For the measurements, 5-10 mg of the samples are weighed into an aluminum crucible. A second unfilled crucible serves as reference for the measurement. The samples are heated at a ramping rate of $10 \mathrm{~K} / \mathrm{min}$ from room temperature to $200^{\circ} \mathrm{C}$ and then they are cooled at the same rate to $-40^{\circ} \mathrm{C}$. A heating rate of $10 \mathrm{~K} / \mathrm{min}$ is chosen because it has shown to not alter the shape or character of the melt endotherm of polypropylene (23). Since polyolefins have a significant difference between a first and a second heat run, the samples are subjected to a second congruent heating run starting at $-40^{\circ} \mathrm{C}$. While the first one mainly serves to eliminate thermal prehistory, only the second heat run is relevant for evaluation.

The rheological properties are measured on a Gemini 150 Advanced Rheometer from Bohlin Instruments. The material is pressed into discs from the molten state $(\emptyset=25.0 \mathrm{~mm}, \mathrm{~d}=2.0 \mathrm{~mm})$ with the press LaboPress 200T from Vogt Labormaschinen $\mathrm{GmbH}$ before measuring. The experiments are carried out with a plate-plate rheometer, which is adjusted to a gap width of $1000 \mu \mathrm{m}$. Due to the process temperature selected for electrospinning, a temperature of $210^{\circ} \mathrm{C}$ is selected for the rheological experiments. The frequency sweeps, which are carried out to characterize the materials on behalf of their zero shear rate viscosity, are preceded by a pre-shearing to ensure the destruction of any additive agglomerates, which could be present in the molten sample. The pre-shearing is performed at a shear rate of $10.0 \mathrm{~s}^{-1}$ for $600 \mathrm{~s}$. The frequency sweeps are performed for an angle frequency at a minimum of $0.6283 \mathrm{rad} / \mathrm{s}$ to a maximum of $500.00 \mathrm{rad} / \mathrm{s}$ and at a deformation of $15 \%$ in an up/down measurement. The zero shear rate viscosity was obtained by applying the Carreau-Yasuda model to the measured data (30).

\subsection{Melt electrospinning process}

For the melt electrospinning process, a syringe pump is used to generate the melt flow, which means the polymer must first be filled into a syringe cylinder. The compounded and granulated material is filled with a spatula into a FORTUNA ${ }^{\circledR}$ OPTIMA ${ }^{\circledR}$ glass syringe (Volume: $10.0 \mathrm{~mL}$ ) and melted in a vacuum furnace (Heraeus ${ }^{\circledR}$ VT $6060 \mathrm{M}$, Thermo Fischer Scientific Inc.) at $210^{\circ} \mathrm{C}$ for approximately $30 \mathrm{~min}$. By applying the vacuum (Diaphragm pump of the type MPC $201 \mathrm{Tp}$, Welch Vacuum), air introduced into the compound is extracted to ensure a continuous melt flow during the electrospinning process. After removal from the oven, the free volume is immediately removed from the syringe by manual pressure on the piston. Cooling takes place at room temperature.

The actual electrospinning setup consists of five main components: temperature control, heating unit, highvoltage generator (HVG-P60-R-EU, Linari Engineering), syringe pump (BSP-99M, Linari Erngineering) and a collector. In order to guarantee a controlled atmosphere, the structure of the present work is extended by a specially designed climate chamber with a separate temperature controller and separate heating unit. In Figure 1 a schematic sketch of the used experimental set-up is shown.

In this study different parameter combinations, relevant for the electrospinning process, are scanned and then analysed. A grid of process parameters comprising collector voltages between 35 and $55 \mathrm{kV}$ ( $2.5 \mathrm{kV}$ increments), a nozzle-collector distance between 5.0 and $12.5 \mathrm{~cm}(2.5 \mathrm{~cm}$ increments) and a climate chamber temperature between room temperature and $120^{\circ} \mathrm{C}\left(20^{\circ} \mathrm{C}\right.$ increments starting at $40^{\circ} \mathrm{C}$ ) is set up and visualized in Figure 2. All selected parameter combinations are restricted on the basis of preliminary spinning tests.

\subsection{Fiber characterization}

The analysis of the fiber diameter is based on scanning electron microscope images. Relevant samples are attached to a specimen holder and sputtered with gold for a period of $30 \mathrm{~s}$ in a Q150T S sputter coater from Quorum Technologies Ltd. The images are taken using the scanning electron microscope (SEM) Gemini SEM from Carl Zeiss AG. An EHT (extra high tension) of $4.0 \mathrm{kV}$ and a 500x or 1000x magnification for overview imaging is used. In addition, detailed images are generated for each sample at 2000x magnification, which are then used to determine the fiber diameter. 20 different fibers per sample are manually measured in diameter. Beads are 


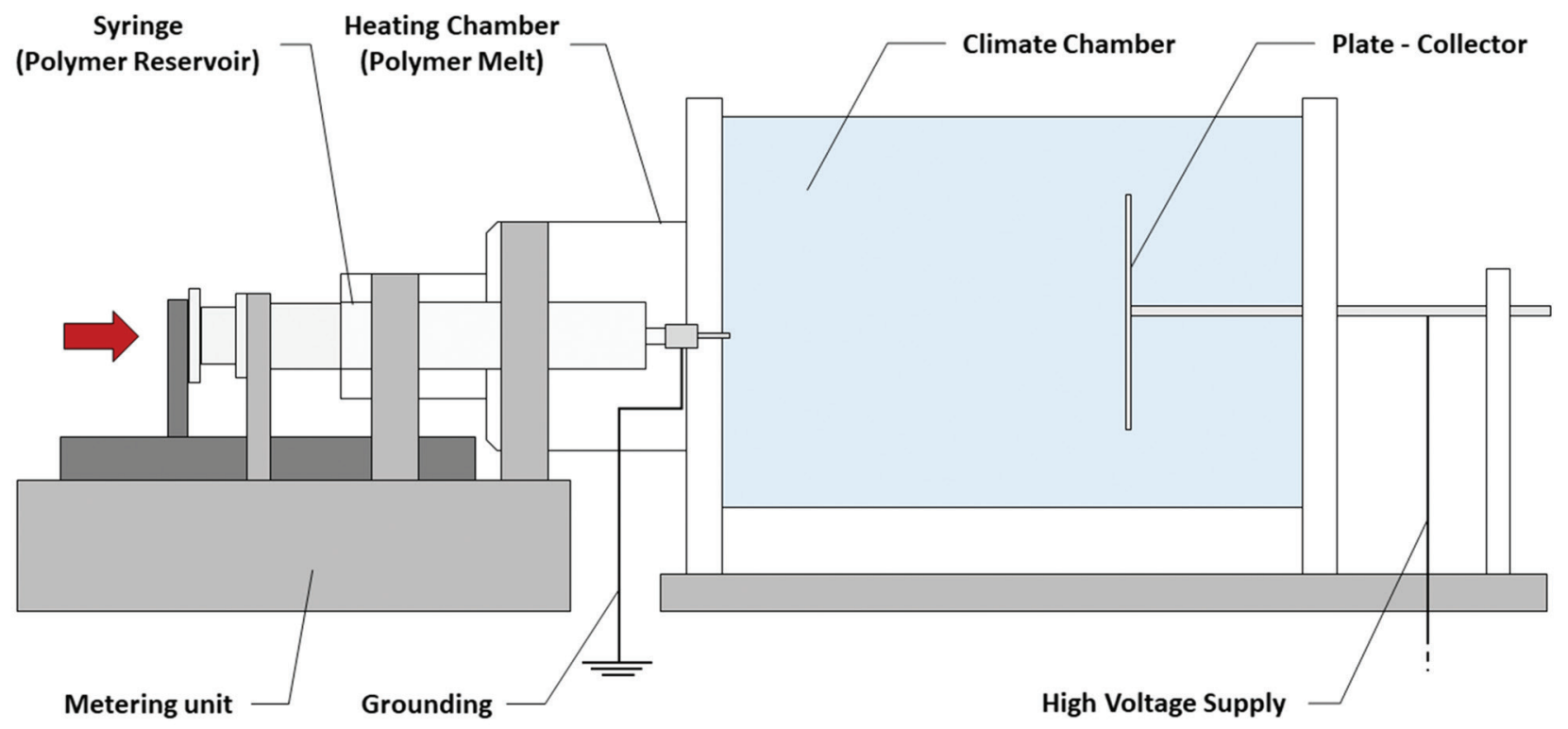

Figure 1: Schematic set-up of the electrospinning system.

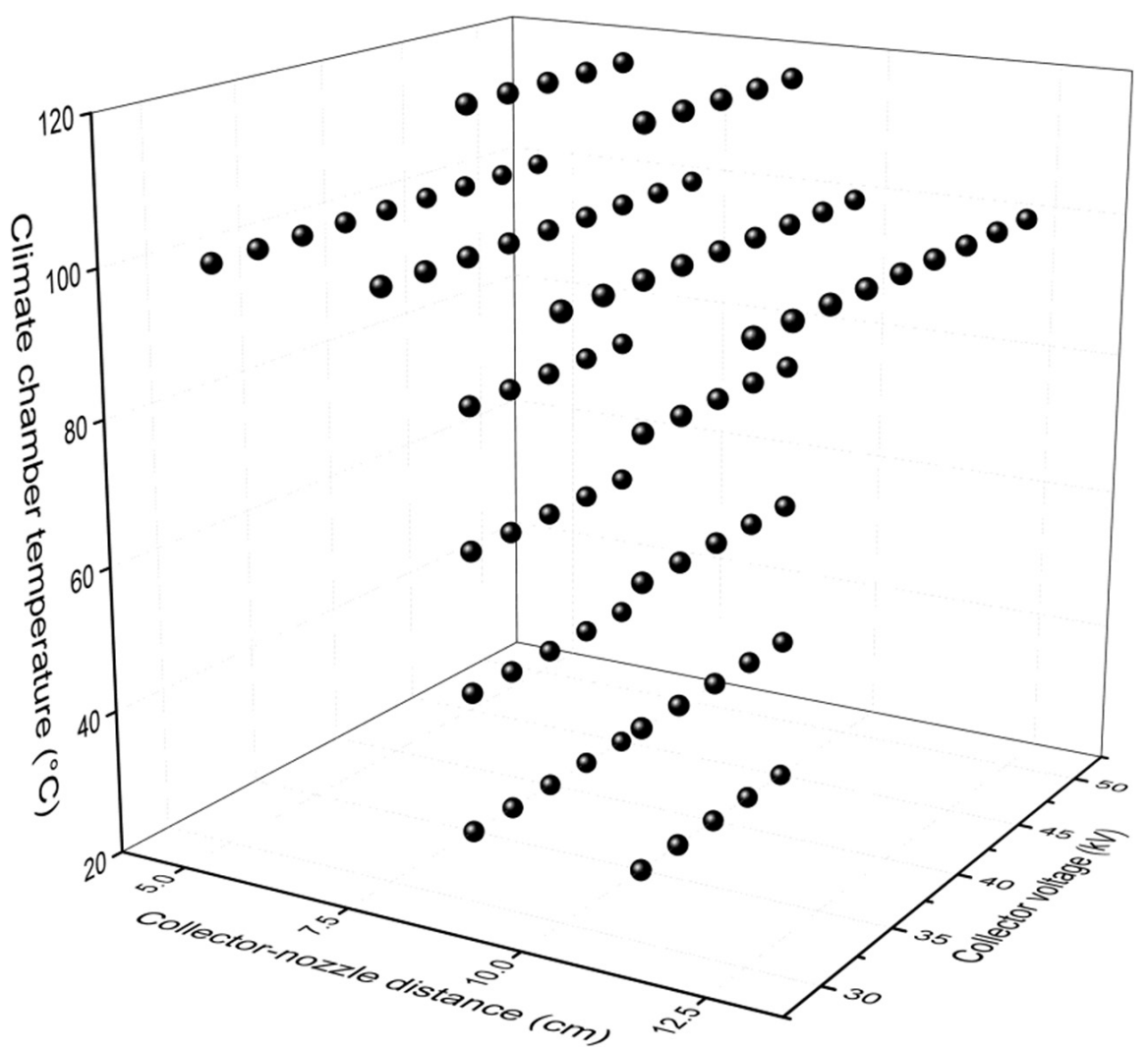

Figure 2: Overview of the process parameter combinations carried out in this study.

not taken into account when analyzing the fiber diameter. The resulting distribution statistics are often presented in the present work on the basis of whisker-box-plot. For each parameter combination (collector voltage, nozzle-collector distance and climate chamber temperature) three independent samples are spun, that means in total 60 fiber diameters and their distribution are measured for each setting. 


\section{Results and discussion}

\subsection{Material choice}

In this study, a meltblown polypropylene is selected as the main component due to its appropriate material properties. This is customised by means of a low viscosity polyolefin to further adapt the polymer to the process. Based on preliminary tests without further additives, an optimum mixing ratio of nine parts polypropylene HL712FB (meltblown component) and one part L-Modu S400 (low viscosity polypropylene) is found as a trade-off between dispersity and spinability. In the following evaluation both composites are considered, but depending on the focus of the analysis one material is presented in more detail. In Table 1 a brief overview of the relevant material parameters from the data sheets is given, showing, among other things, the great difference in melt flow index and molar mass of the two raw polymers.

Irgastat ${ }^{\circledR}$ P 16 is used due to its process-optimising influence. In previous experiments the effect of the additive is analysed and its reducing influence on electric resistivity is confirmed (28). Hence, the additive is stabilising the process and enables a homogenous fiber production in some composite combinations. An ideal additive concentration is found at $2 \mathrm{wt} \%$ for the present application. The second additive sodium stearate is added in different contents to optimize the electrical conductivity of the spinning material.

\subsection{Material characterization}

An effect of the additives on the melting temperature of the polypropylene should be excluded by means of DSC measurements. It is shown that none of the added additives, neither sodium stearate nor Irgastat ${ }^{\circledR}$ P 16 , has a significant influence on the melting temperature. The

Table 1: Overview of relevant material properties $(15,16)$.

\begin{tabular}{lrrrr}
\hline Polypropylene & $\begin{array}{r}\text { Melt Flow } \\
\text { Index } \\
(\mathbf{g} / \mathbf{1 0} \mathbf{m i n})\end{array}$ & $\begin{array}{r}\text { Melting } \\
\text { Point } \\
\left({ }^{\circ} \mathrm{C}\right)\end{array}$ & $\begin{array}{r}\text { Molar Mass } \\
(\mathbf{k g} / \mathbf{m o l})\end{array}$ & $\begin{array}{r}\text { Zero Shear } \\
\text { Rate Viscosity } \\
\left(\mathbf{P a}^{*} \mathbf{s}\right)\end{array}$ \\
\hline $\begin{array}{l}\text { Borealis } \\
\text { HL712FB }\end{array}$ & 1200 & 158.0 & $125.7 \pm 1.7^{1}$ & $\mathrm{~N} / \mathrm{A}$ \\
L-Modu S400 & 2600 & 80.0 & $45.0^{2}$ & $8.5\left(190^{\circ} \mathrm{C}\right)$ \\
\hline
\end{tabular}

${ }^{1}$ measured at the Institute for Polymer Materials, Friedrich-Alexander University Erlangen-Nuremberg according to the measuring method of (31).

${ }^{2}$ taken from the manufacturer's data sheet (26).
DSC curves show endotherm melting peaks in a range of approximately 150.0 to $160.0^{\circ} \mathrm{C}$, which can be compared to the manufacturer's specification $\left(158.0^{\circ} \mathrm{C}-\mathrm{HL} 712 \mathrm{FB}\right)$. The endotherm melting peak splits into a double peak, which can be explained by two crystal phases of the polypropylene. The curves of the $2^{\text {nd }}$ heat run are shown in Figure 3 for the two pure polyolefin and for both polymer matrixes with $4 \mathrm{wt} \%$ sodium stearate and $2 \mathrm{wt} \%$ Irgastat ${ }^{\circledR}$ P 16.

It has to be mentioned that the viscosity is one of the main influence parameters in electrospinning studies, but in the following analysis only a brief overview is given in regard to this parameter: The lower the viscosity the better the processing and the smaller the fiber diameter. However, the electrical conductivity is opposed to the viscosity, the sodium stearate, which is added for the increase in electrical conductivity, also increases the viscosity. The additive Irgastat ${ }^{\circledR}$ P 16 should not have a significant influence on the viscosity of the material compound, which is also checked in pre-examinations. Therefore, an optimum of the sodium stearate concentration has to be found during the experimental work.

\subsection{Influence of the climate chamber temperature}

To determine the influence of the climate chamber temperature polypropylene HL712FB with $4 \mathrm{wt} \%$ sodium stearate and $2 \mathrm{wt} \%$ Irgastat ${ }^{\circledR} \mathrm{P} 16$ is selected. The nozzle-collector distance and applied voltage are varied between 7.5 and $10.0 \mathrm{~cm}$ and between 35.0 and $45.0 \mathrm{kV}$ respectively. However, it is crucial that in this part of the experimental sequence, the temperature of the climate chamber is gradually increased from room temperature to $120^{\circ} \mathrm{C}$. Figure 4 shows the determined fiber diameters as a function of the chamber temperature. In order to ensure good comparability, the mean values of the fiber diameters always refer to the same parameter combination in this diagram (nozzle-collector distance $10.0 \mathrm{~cm}$, voltage applied $40.0 \mathrm{kV}$ ).

The results verify the chamber temperature as a dominant factor for regulating the fiber diameter in melt electrospinning. A low temperature inside the climate chamber results in a faster solidification of the polymer and limits the stretching of the fiber. Therefore, only a median fiber diameter of $2735 \mathrm{~nm}$ can be achieved at a climate chamber temperature of $20^{\circ} \mathrm{C}$. Increasing the chamber temperature delays the solidification process of the polymer melt during the spinning and thus enables a stronger stretching of the fibers. In this way, finer and more 


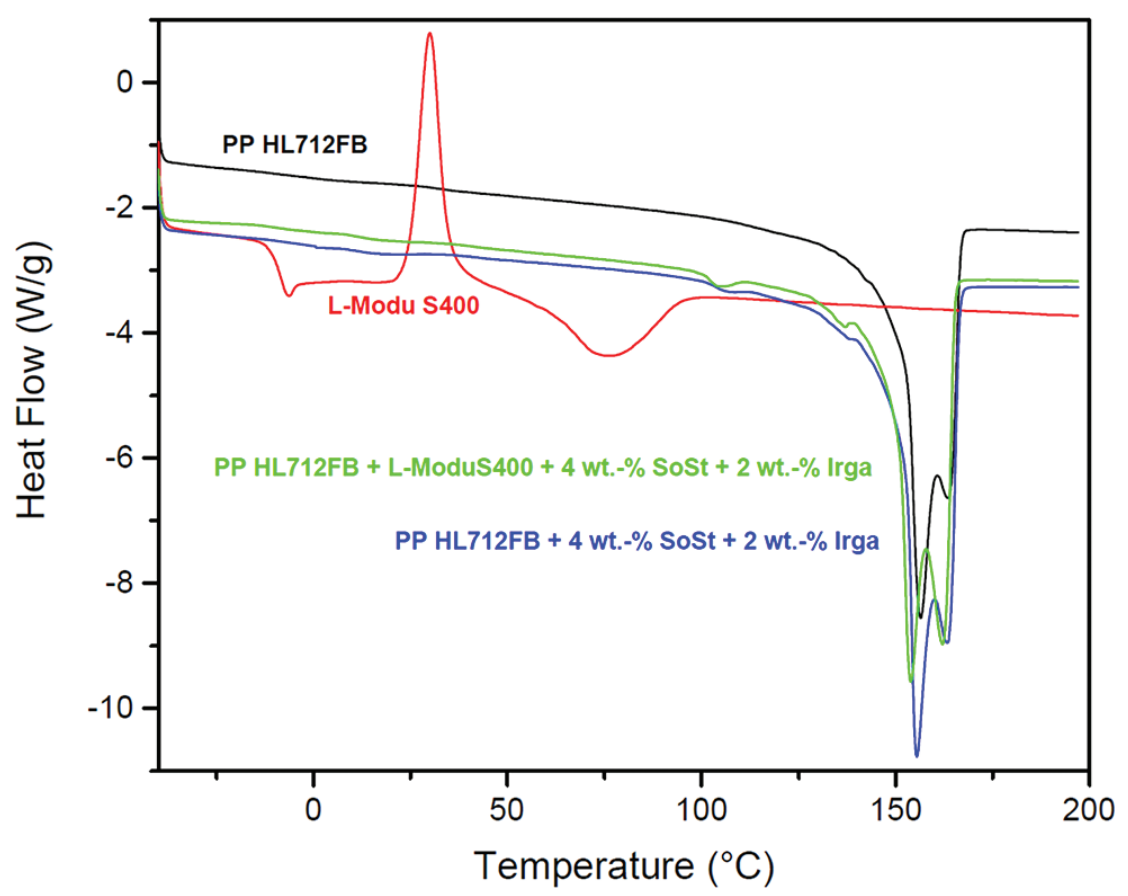

Figure 3: DSC diagram of 2nd heat run PP HL712FB, L-Modu S400 and related compounds with 4 wt $\%$ sodium stearate (SoSt) and 2 wt $\%$ Irgastat $\circledast$ P 16 (Irga).

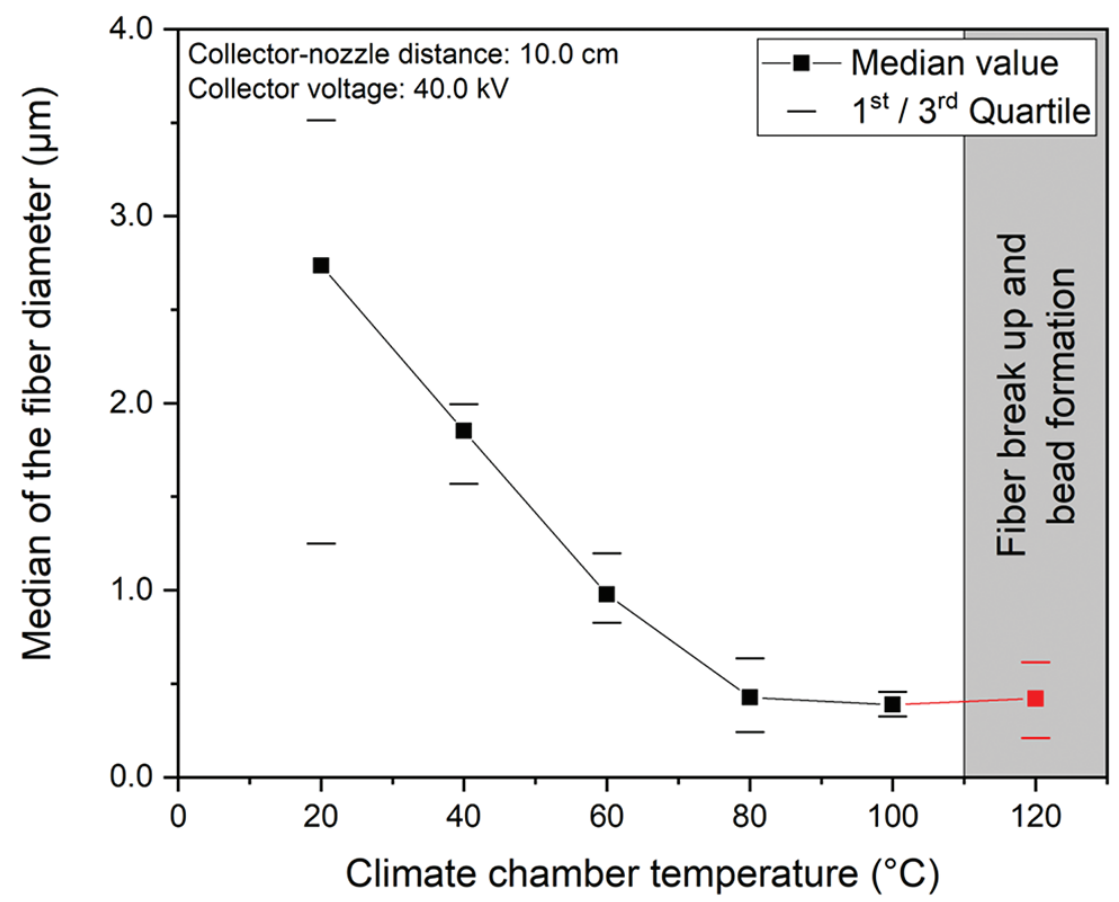

Figure 4: Fiber diameter in relation to the climate chamber temperature.

uniform fibers can be produced. At a chamber temperature of $100^{\circ} \mathrm{C}$ a minimum of approximately $388 \mathrm{~nm}$ is achieved while a further reduction is limited by fiber break up and bead formation as shown in Figure 4. Figures 5a-c show an example of a detailed SEM image of a sample spun at a chamber temperature of 40,60 and $100^{\circ} \mathrm{C}$ respectively. However, if the temperature in the climatic chamber is raised to $120^{\circ} \mathrm{C}$, the fiber diameter will increase again. The reason for this is that the melted state of the polymer is maintained for too long, the fiber in the tension field tapers 

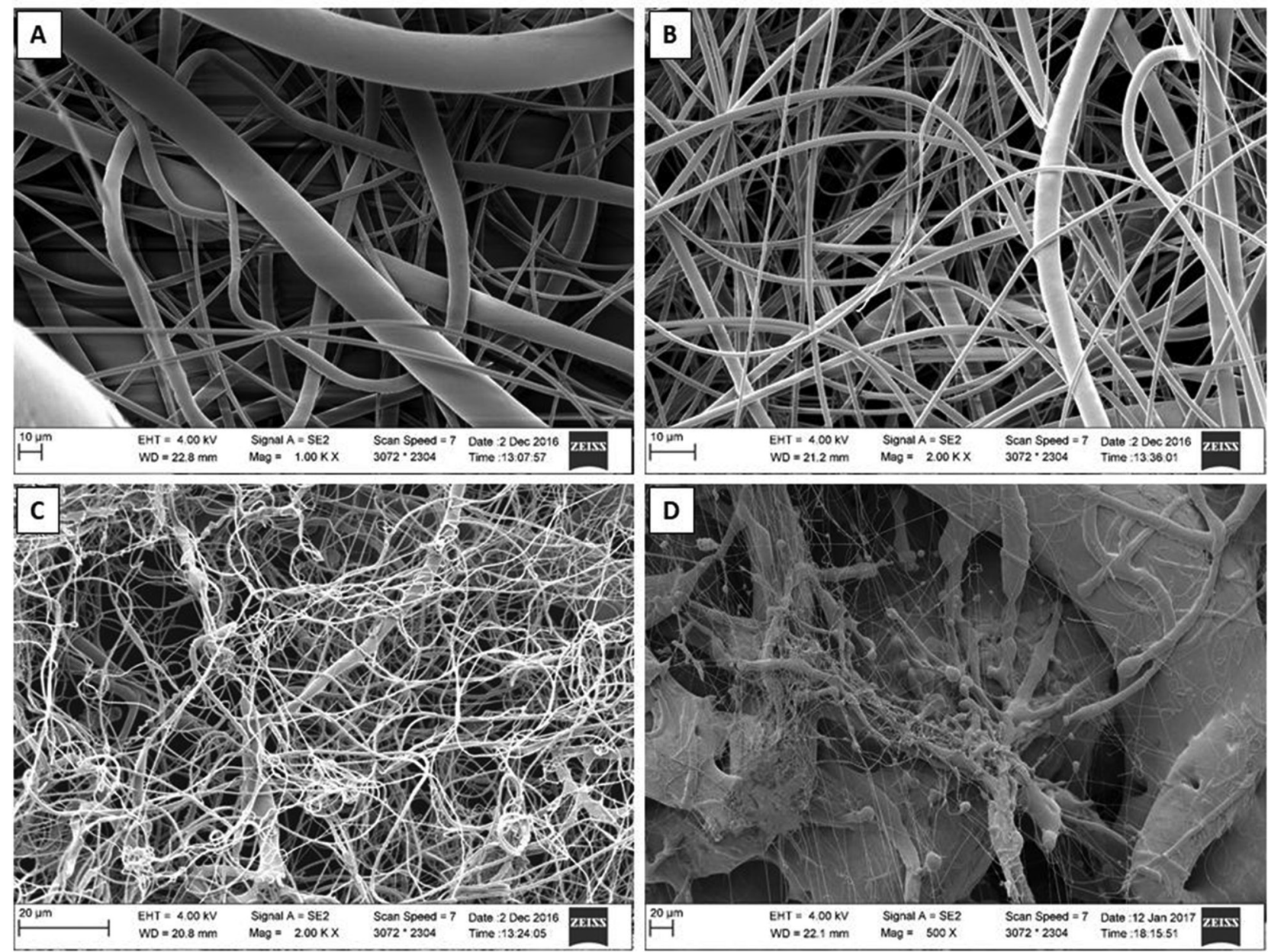

Figure 5: SEM-images of fiber samples at a climate chamber temperature of (a) $40^{\circ} \mathrm{C}$, (b) $60^{\circ} \mathrm{C}$, (c) $100^{\circ} \mathrm{C}$ and (d) $120^{\circ} \mathrm{C}$.

further and finally breaks off. The presence of an excessively high chamber temperature thus significantly impedes the commencement of a continuous spinning process and results in increased formation of beads (see Figure $5 \mathrm{~d}$ ). Since beads are not taken into account when determining the median of the fiber diameter, the result is strongly distorted and therefore highlighted in grey in Figure 4. Thus, $100^{\circ} \mathrm{C}$ is the optimum temperature within the climatic chamber to ensure the production of fine and homogeneous fibers with the chosen material. For the material compound with nine parts polypropylene HL712FB and one part L-Modu S400 a similar behavior is found.

\subsection{Fiber diameter dependency on the electrical field}

The quotient of collector voltage and nozzle-collector distance is defined by the physical parameter of the electric field, which is used for evaluation in this section. Data clusters are revealed at the four nozzlecollector distances. The results are again presented for the compound of polypropylene HL712FB, $4 \mathrm{wt} \%$ sodium stearate and $2 \mathrm{wt} \%$ Irgastat ${ }^{\circledR} \mathrm{P} 16$.

In Figure 6 the process limits are indicated by empirically defined lines (grey lines). For each nozzlecollector distance a characteristic maximal and minimal collector voltage can be defined experimentally, that means if the collector voltage is too low no fiber formation is possible and if the collector voltage exceeds its maximum no stable process can be obtained due to the tearing off of the filaments. The process is thus limited to an electric field strength from $3.0 \mathrm{kV} / \mathrm{cm}$ up to $8.0 \mathrm{kV} / \mathrm{cm}$.

From Figure 6 it is evident that each data cluster for a constant nozzle-collector distance can be described by a linear function within the experimental error. Remarkable is the fact that all linear descriptions in Figure 6 for each cluster have a common intersection point at the boundary given by minimum needed electrical field and maximum fiber diameter $(3.0 \mathrm{kV} / \mathrm{cm}$ and $600 \mathrm{~nm})$. 


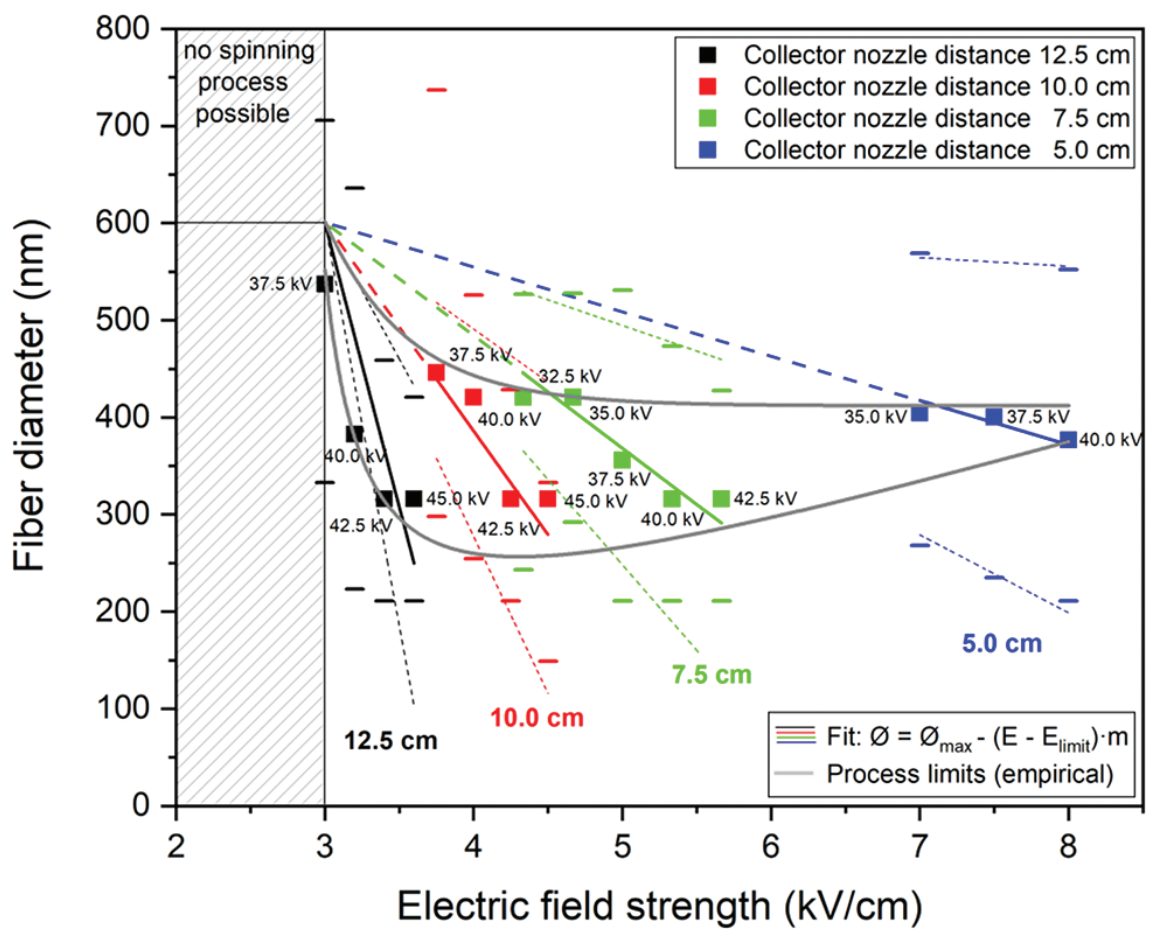

Figure 6: Correlation between the median of the fiber diameter and the electric field strength with marking of the process limits.

If only the results for a selected nozzle-collector distance are considered, the influence of the collector voltage becomes apparent. The higher the collector voltage within the processing limits, the more the filament is stretched and the fiber diameter decreases. This phenomena is fitted linearly by Eq. 1 (solid lines correspond to median values and dashed lines to quartile values):

$$
\Phi=\Phi_{\max }-\left(E-E_{\text {process limit }}\right) \cdot m,
$$

where $\Phi_{\max }$ represents the maximal fiber diameter in the process window range, $\mathrm{E}_{\text {process limit }}$ is given by the lowest possible electric field strength of $3.0 \mathrm{kV} / \mathrm{cm}$ and $\mathrm{m}$ corresponds to the slope. The minimal fiber diameter can be found for a parameter combination of a collector-nozzle distance of $10.0 \mathrm{~cm}$ and a collector voltage of $45.0 \mathrm{kV}$, which can be seen in Figure 6. For these given parameter a fiber diameter of $316 \mathrm{~nm}$ for the neat polypropylene HL712FB matrix can be reached.

In Figure 7, the fit parameter m, extrapolated from the data evaluation in Figure 6, is plotted against the nozzle-collector distance. It shows to what extent the fiber diameter can be influenced by varying the electric field or the collector voltage. The greatest potential is again shown here by a nozzle-collector distance of $10.0 \mathrm{~cm}$ having a high slope value $\mathrm{m}$ and a small standard deviation. The standard deviation is significantly larger for the next analyzed nozzlecollector distance of $12.5 \mathrm{~cm}$.

\subsection{Influence of the sodium stearate concentration on the fiber diameter}

Now the focus is turned to the concentration of the electrical conductivity filler sodium stearate and its influence on the fiber diameter. For both polypropylene combinations, neat HL712FB and the combination with L-Modu S400, an optimum can be found. Depending on both material parameters, viscosity and electrical conductivity which are influenced by the additive sodium stearate, a minimum of the fiber diameter can be obtained (see Figure 8). At first, an increasing concentration of sodium stearate correlates with a decrease in the fiber diameter until it appears that the increasing viscosity becomes the dominant influencing factor and the fiber diameter increases again. The zero shear rate viscosity decreases with increasing additive concentration illustrated in Figure 8.

The minimum fiber diameter can be found for neat polypropylene of the type HL712FB with $4 \mathrm{wt} \%$ sodium stearate and $2 \mathrm{wt} \% \operatorname{Irgastat} \AA \mathrm{P} 16$ at a median diameter of $316 \mathrm{~nm}$ and for the mixture of nine parts polypropylene 


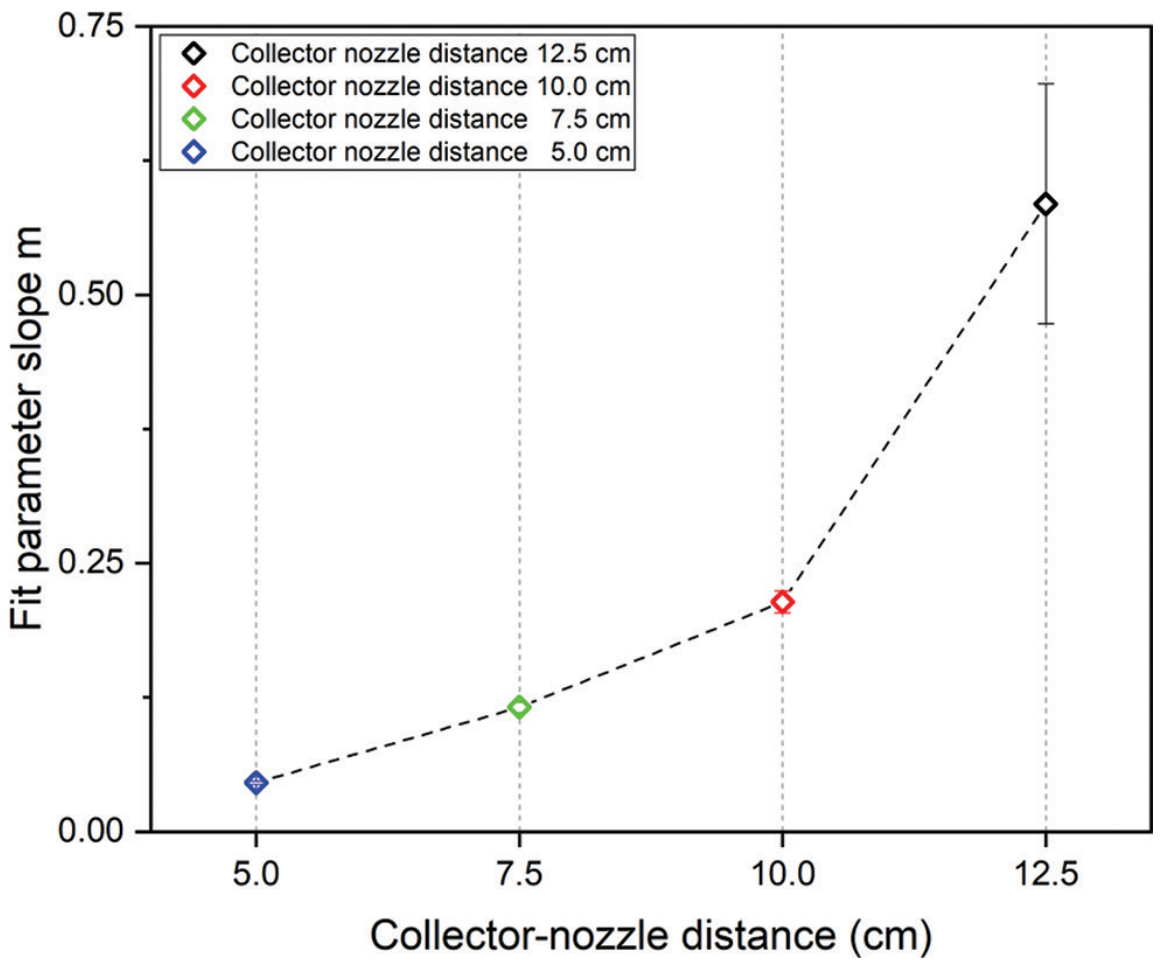

Figure 7: Fit parameter slope $\mathrm{m}$ versus the collector nozzle distance.

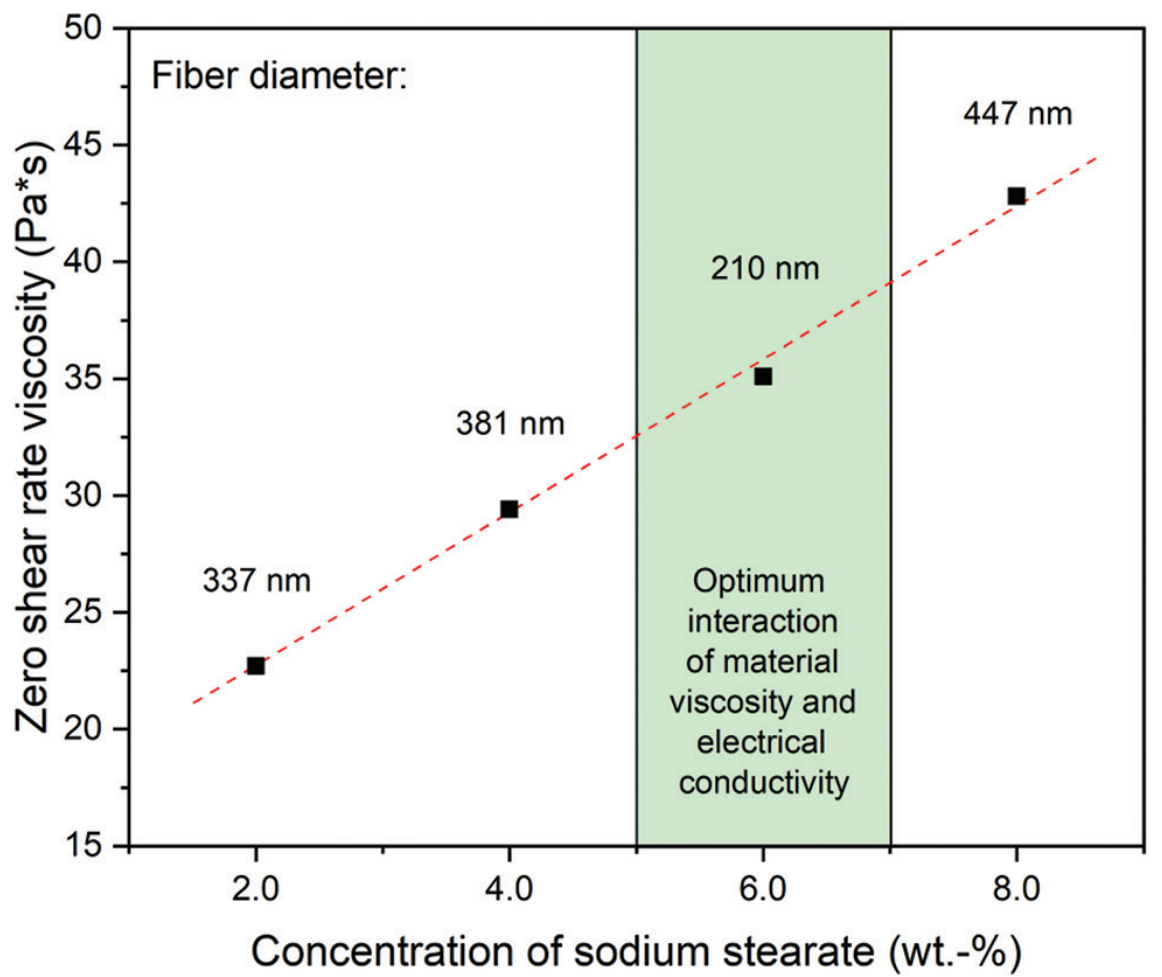

Figure 8: Zero shear rate viscosity of the compounds related to the concentration of sodium stearate with indicated fiber diameter.

HL712FB and one part polypropylene L-Modu S400 a median diameter of $210 \mathrm{~nm}$ is achieved with a sodium stearate concentration of $6 \mathrm{wt} \%$. In both cases the experiments are carried out with a climate chamber temperature of $100^{\circ} \mathrm{C}$, a collector voltage of $45.0 \mathrm{kV}$ and a nozzle-collector distance of $10.0 \mathrm{~cm}$. 


\section{Conclusion}

One of the biggest modification in the process is the climate chamber, which allows a regulation of the ambient temperature during spinning. The temperature is evaluated from room temperature and measured in $20^{\circ} \mathrm{C}$ intervals up to $120^{\circ} \mathrm{C}$. A steady decrease of the fiber diameter can be observed with a homogeneous spinning quality and a minimal fiber diameter at $100^{\circ} \mathrm{C}$ for both polypropylene compositions with additives.

A correlation is given for melt electrospinning describing the influence of electrical field strength and nozzle-collector distance. A unique intersection point is revealed at the minimum needed electrical field strength for a stable process and the maximal fiber diameter for all variations of electrical field and nozzle-collector distance. However, for a nozzle-collector distance of $10.0 \mathrm{~cm}$ and a collector voltage of $45.0 \mathrm{kV}$ the best results are obtained.

For each polypropylene composition an optimal additive content of sodium stearate can be evaluated. Therefore, the minimal fiber diameter can be found for neat polypropylene of the type HL712FB with $4 \mathrm{wt} \%$ sodium stearate and $2 \mathrm{wt} \%$ Irgastat ${ }^{\circledR} \mathrm{P} 16$ with a minimum median diameter of $316 \mathrm{~nm}$. The average fiber diameter of Nayak et al. of $310 \mathrm{~nm}$ using sodium chloride as an additive could thus be confirmed (23). For the mixture of nine parts polypropylene HL712FB and one part polypropylene L-Modu S400 the minimal obtained median fiber diameter was further reduced to $210 \mathrm{~nm}$, achieved with a content of $6 \mathrm{wt} \%$ sodium stearate and $2 \mathrm{wt} \% \operatorname{Irgastat}{ }^{\circledR} \mathrm{P} 16$. The median fiber diameter of $210 \mathrm{~nm}$ is the finest possible fiber diameter that could be achieved in all test series with consideration of a homogeneous fiber quality.

Acknowledgement: This study on optimizing the melt electrospinning process of polypropylene is driven by the aim to minimize the fiber diameter and process homogeneity. There is no conflict of interest with a project funded by the AiF Projekt $\mathrm{GmbH}$, completed in February 2017, (title: "ZIM - E-Feld"; reference: KF 2793404RE4) on the upscaling process of melt electrospinning, which was carried out as a "FuE-Kooperationsprojekt" of the "Zentrales Innovationsprogramm Mittelstand (ZIM)".

\section{References}

1. Fourné F., Synthetische Fasern: Herstellung, Maschinen und Apparate, Eigenschaften; Handbuch für Anlagenplanung, Maschinenkonstruktion und Betrieb. Carl Hanser Verlag, München, Wien, 1995, 894 p.
2. Fuchs H., Albrecht W., Vliesstoffe: Rohstoffe, Herstellung, Anwendung, Eigenschaften, Prüfung. 2nd Edition. Wiley-VCH Verlag GmbH Co. KGaA, Weinheim, 2012, 728 p.

3. Watanabe K., Nakamura T., Kim B.S., Kim I.S., Development of polypropylene nanofiber production system. Polym. Rev., 2011, 51(3), 288-308.

4. Nayak R., Padhye R., Kyratzis I.L., Truong Y.B., Arnold L., Recent advances in nanofibre fabrication techniques. Text. Res. J., 2011, 82(2), 129-147.

5. Ramakrishna S., Fujihara K., Teo W., Lim T., Ma Z., An introduction to electrospinning and nanofibers. World Scientific Pub Co Inc., Singapore, 2005, $396 \mathrm{p}$.

6. Hutmacher D.W., Dalton P.D., Melt Electrospinning. Chem. Asian. J., 2011, 6(1), 44-57.

7. Formhals A., Process and apparatus for preparing artificial threads. United States patent US 1975504A, Mainz, Germany, 1934.

8. Larrondo L., Manley R.S.J., Electrostatic fiber spinning from polymer melts. I. Experimental observations on fiber formation and properties. J. Polym. Sci. B Polym. Phys., 1981, 19(6), 909-920.

9. Larrondo L., Manley R.S.J., Electrostatic fiber spinning from polymer melts. II. Examination of the flow field in an electrically driven jet. J. Polym. Sci. B Polym. Phys., 1981, 19(6), 921-932.

10. Larrondo L., Manley R.S.J., Electrostatic fiber spinning from polymer melts. III. Electrostatic deformation of a pendant drop of polymer melt. J. Polym. Sci. B Polym. Phys., 1981, 19(6), 933-940.

11. Nayak R., Padhye R., Kyratzis I.L., Truong Y.B., Arnold L., Effect of viscosity and electrical conductivity on the morphology and fiber diameter in melt electrospinning of polypropylene. Text. Res. J., 2012, 83(6), 606-618.

12. Lyons J., Li C., Ko F., Melt-electrospinning part I: processing parameters and geometric properties. Polym., 2004, 45, 7597-7603.

13. Zhou H., Green T.B., Joo Y.L., The thermal effects on electrospinning of polylactic acid melts. Polym., 2006, 47(21), 7497-7505.

14. Watanabe K., Nakamura T., Kim B.S., Kim I.S., Effect of organic solvent on morphology and mechanical properties of electrospun syndiotactic polypropylene nanofibers. Polym. Bull., 2011, 67(9), 2025-2033.

15. van Reenen A.J., Keulder L., Solution Electrospinning of Polyolefins: The Effect of Comonomers in Propylene/ $\alpha$-Olefin Copolymers. Macromol. Mater. Eng., 2010, 295(7), 666-670.

16. Cho D., Zhou H., Cho Y., Audus D., Joo Y.L., Structural properties and superhydrophobicity of electrospun polypropylene fibers from solution and melt. Polym., 2010, 51(25), 6005-6012.

17. Maeda T., Takaesu K., Hotta A., Syndiotactic polypropylene nanofibers obtained from solution electrospinning process at ambient temperature. J. Appl. Polym. Sci., 2016, 133(13), 43238-43245.

18. Cao L., Dong M., Zhang A., Liu Y., Yang W., Su Z., et al., Morphologies and Crystal Structures of Styrene-Acrylonitrile/ Isotactic Polypropylene Ultrafine Fibers Fabricated by Melt Electrospinning. Polym. Eng. Sci., 2013, 53, 2674-2682.

19. Cao L., Su D., Su Z., Chen X., Morphology, Crystallization Behavior and Tensile Properties of $\beta$-Nucleated Isotactic Polypropylene Fibrous Membranes Prepared by Melt Electrospinning. Chin. J. Polym. Sci., 2014, 32(9), 1167-1175. 
20. Cao L., Su D., Su Z., Chen X., Fabrication of Multiwalled Carbon Nanotube/Polypropylene Conductive Fibrous Membranes by Melt Electrospinning. Ind. Eng. Chem. Res., 2014, 53(6), 2308-2317.

21. Fang J., Zhang L., Sutton D., Wang X., Lin T., Needleless Melt-Electrospinning of Polypropylene Nanofibres. J. Nanomater., 2012, 1-9.

22. Dalton P.D., Grafahrend D., Klinkhammer K., Klee D., Möller M., Electrospinning of polymer melts: Phenomenological observations. Polym., 2007, 48(23), 6823-6833.

23. Nayak R., Kyratzis I.L., Truong Y.B., Padhye R., Arnold L., Melt-electrospinning of polypropylene with conductive additives. J. Mater. Sci., 2012, 47(17), 6387-6396.

24. Chen Z., He J., Zhao F., Liu Y., Liu Y., Yuan H., Effect of polar additives on melt electrospinning of non-polar Polypropylene. J. Serb. Chem. Soc., 2014, 79(5), 587-596.
25. Borealis A.G., Polypropylene HL712FB [Datasheet]. 2014.

26. Idemitsu Kosan Co Ltd. Polypropylene L Modu ${ }^{\mathrm{TM}}$ S400 [Data sheet]. 2017.

27. Alfa Aesar. Product Specification: Sodium Stearate [Data sheet]. 2015.

28. BASF AG. Technische Informationen Irgastat ${ }^{\circledR}$ P [Data sheet]. 2010.

29. Domininghaus H., Zusatzstoffe für Kunststoffe. Zechner \& Hüthig Verlag GmbH, Speyer am Rhein, 1978, $131 \mathrm{p}$.

30. Carreau P.J., Rheological Equations from Molecular Network Theories. T. Soc. Rheol., 1972, 16(1), 99-128.

31. Lanyi F.J., Kunzelmann P., Schubert D.W., Novel Chart for Representation of Material Performance and Reliability. Macromol. Symp., 2016, 365(1), 194-202. 